\title{
Physical Performance and Anthropometric Characteristics of Male South African University Soccer Players
}

\author{
by \\ Alliance Kubayi ${ }^{1}$, Yvonne Paul ${ }^{1}$, Prescott Mahlangu ${ }^{1}$, Abel Toriola ${ }^{1}$
}

\begin{abstract}
Soccer is the most popular sport worldwide. Despite its global acclaim, scientific studies of soccer have tended to focus on tactics and techniques, thereby neglecting the physical and physiological profile of the players. Therefore, the purpose of this study was to examine physical and anthropometric characteristics of male South African university soccer players. Twenty-seven male soccer players aged 19 to 24 (mean age: 22.1 years; $s=1.5$ years) volunteered to participate in the study. The results showed that goalkeepers $(77.5 \pm 9.7 \mathrm{~kg})$ and defenders $(68.2 \pm 6.5 \mathrm{~kg})$ were the heaviest compared to players in other playing positions. The goalkeepers also had the highest percentage of body fat $(11.3 \pm 2.3 \%)$, in contrast to midfielders who had the lowest body fat content $(9.1 \pm 0.9 \%)$. With regard to flexibility, defenders $(45.1 \pm 4.9 \mathrm{~cm})$ and midfielders $(45.9 \pm 5.4 \mathrm{~cm})$ performed better than goalkeepers $(37.1 \pm 4.3 \mathrm{~cm})$ and strikers $(40.1 \pm 3.4 \mathrm{~cm})$. Midfielders $\left(57.2 \pm 3.1 \mathrm{ml}^{-1} \cdot \mathrm{kg}^{-1} \cdot \mathrm{min}^{-1}\right)$ and defenders $\left(56.1 \pm 5.1 \mathrm{ml}^{-1} \cdot \mathrm{kg}^{-1} \cdot \mathrm{min}^{-1}\right)$ had significantly higher values of maximal oxygen uptake $\left(V \mathrm{~V}_{2 \max }\right)$ than goalkeepers $\left(47.9 \pm 0.2 \mathrm{ml}^{-1} \cdot \mathrm{kg}^{-1} \cdot \mathrm{min}^{-1}\right)$ and strikers $(49.8 \pm 6.2$ $\left.\mathrm{ml}^{-1} \cdot \mathrm{kg}^{-1} \cdot \mathrm{min}^{-1}\right)$. No significant $(p>0.05)$ differences were observed for all other variables, with the exception of body height, body mass, and $\mathrm{VO}_{2 \max }$. It was therefore concluded that sports scientists and coaches should tailor conditioning programmes in soccer according to players' positions in view of the implications for successful performance.
\end{abstract}

Key words: soccer, physical fitness, anthropometric characteristics, performance.

\section{Introduction}

Soccer is the most popular sport in the world, with the FIFA World Cup usually attracting millions of spectators (Clark, 2007; Reilly et al., 2000). Despite its global acclaim, studies have often focused on tactics and techniques at the expense of physical factors (Helgerud et al., 2001). Williams and Franks (1998) are of the view that psychological, perceptual, technical, anthropometric and physiological factors must all be highly developed to reach an elite performance level. Therefore, in order to be successful, soccer players need the finest combination of tactical, technical, mental and physical characteristics (Bangsbo, 1994). Consequently, it is important to understand the determinants of success in soccer, such as the physical performance and anthropometric characteristics required of players in specific positions.

Soccer players are categorised into four groups: goalkeepers, defenders, midfielders and forwards. Therefore, players in the various positions have different position-specific physical performance and anthropometric characteristics required for success. For example, the midfielders run the longest distances compared to forwards or defenders (Bangsbo et al., 1991). In their study of Nigerian university soccer players, Adeniran et al. (2009) found that midfielders were lightest and shortest and had the least percentage of body fat compared to those in the other playing positions (i.e. goalkeepers, defenders and forwards). The forwards were significantly lighter than defenders and goalkeepers. The goalkeepers were the tallest,

1 - Department of Sport, Rehabilitation and Dental Sciences, Tshwane University of Technology, South Africa. 
heaviest and had the highest fat content (Adeniran et al., 2009).

Although soccer is the most popular sport in South Africa (Kubayi et al., 2015), very few studies, if any, have assessed the physical performance and anthropometric characteristics of university soccer players in the country. Whilst many previous studies (e.g., Casajús, 2001; Clark, 2010; Kashani et al., 2013; Reilly et al., 2010) have focussed on national soccer teams and those in professional leagues, there is limited information on university soccer players who also have the potential for selection into national teams for future development. In fact, according to Gil et al. (2010), most of the studies on soccer have been based on elite players, and there is very little research concerning amateur soccer players who have great prospects for professional development. Therefore, this study attempts to fill the gap in the literature by examining the physical fitness levels among university soccer players according to their playing positions.

The results of this study could therefore provide soccer coaches and trainers with valuable information on how to efficiently and effectively plan and implement strategies for university soccer players. Such information may also be useful in understanding the physical fitness profiles of soccer players in different positions so that coaches and sports scientists can direct position-specific conditioning programmes appropriately to maximise successful performance.

\section{Methods}

\section{Subjects}

Twenty-seven male soccer players from a South African university volunteered to participate in the study. The players were grouped according to playing positions: goalkeepers, defenders, midfielders and forwards. The players' ages ranged from 19 to 24 years (mean age: 22.1 years; $s=1.5$ years). Prior to physical fitness testing, all players provided informed consent. Ethical clearance was obtained from the Faculty of Science Committee for Research Ethics, Tshwane University of Technology, Pretoria, South Africa.

\section{Testing procedure}

Anthropometry.

All the anthropometric variables (i.e. body height, body mass, body mass index and body adiposity) were measured following the standard procedures of the International Society for the Advancement of Kinanthropometry (ISAK) as outlined by Marfell-Jones et al. (2006). A stadiometer and a calibrated scale were used to measure body height and mass of each player to the nearest $0.1 \mathrm{~cm}$ and $0.1 \mathrm{~kg}$, respectively. The body mass index (BMI) was calculated from body height and mass $\left(\mathrm{kg} / \mathrm{m}^{2}\right)$. The percentage of body fat $(\% \mathrm{BF})$ was calculated from the sum of seven skinfolds (biceps, triceps, suprailiac, abdominal, subscapular, front thigh and medial calf) using a Harpenden skinfold calliper (Ross and MarfellJones, 1991). All the anthropometric measurements were performed by a qualified ISAK Level 2 Kinanthropometrist.

Physical performance measures.

Flexibility was measured using the sitand-reach test (Ellis et al., 2000), which has testretest reliability of 0.89 (Johnson and Nelson, 2000). The total displacement of the fingertips between reach and stretch distance was recorded to the nearest $0.5 \mathrm{~cm}$, and the best of three trials was accepted as the final score (Clark, 2007). The number of sit-ups and push-ups performed per minute was recorded for each player (Jackson et al., 1994). Agility was measured using the T-Test and the best times of three successful trials (to the nearest $0.1 \mathrm{~s}$ ) were recorded. Sprint tests were used to assess players' speed $(40 \mathrm{~m})$. Each player was allowed three attempts, with a 2-min rest in between. The best result of the three attempts was registered for further analysis (Rebelo et al., 2010). Aerobic capacity was determined using a multistage shuttle run test, which involved continuous running between two restraining lines $20 \mathrm{~m}$ apart in order to estimate maximal oxygen uptake $\left(\mathrm{VO}_{2 \max }\right)$ (Ramsbottom et al., 1988).

\section{Statistical analysis}

The players' anthropometric and performance characteristics were analysed descriptively (i.e. mean and standard deviations). In addition, a one-way analysis of variance (ANOVA) was undertaken to evaluate the differences in the dependent measures based on playing positions. If the result was significant, Tukey HSD post hoc analysis was carried out to determine specific substantial differences among the groups. A probability level of 0.05 or less was taken to indicate statistical significance. All data 
were analysed using the Statistical Package for the Social Sciences (SPSS) (SPSS Inc., Chicago, IL, USA, version 23.0).

\section{Results}

Table 1 shows the physical and anthropometric characteristics of the male university soccer players. Of all the groups, the goalkeepers were the tallest $(178.8 \pm 4.8 \mathrm{~cm})$, heaviest $(77.5 \pm 9.7 \mathrm{~kg})$ and had the highest percentage of body fat $(11.3 \pm 2.3 \%)$. The midfielders were the shortest $(165.1 \pm 6.1 \mathrm{~cm})$ and had the lowest percentage of body fat $(9.1 \pm 0.9 \%)$ compared to those in the other playing positions. The strikers $(60.2 \pm 9.5 \mathrm{~kg})$ were lighter than the defenders $(68.2 \pm 6.5 \mathrm{~kg})$, midfielders $(63.2 \pm 6.5$ $\mathrm{kg})$ and goalkeepers $(77.5 \pm 9.7 \mathrm{~kg})$. With regard to flexibility, the defenders $(45.1 \pm 4.9 \mathrm{~cm})$ and midfielders $(45.9 \pm 5.4 \mathrm{~cm})$ performed better than the goalkeepers $(37.1 \pm 4.3 \mathrm{~cm})$ and strikers $(40.1 \pm$ $3.4 \mathrm{~cm}$ ). Highest values of $\mathrm{VO}_{2}$ max were also found among midfielders $\left(57.2 \pm 3.1 \mathrm{ml}^{-1} \cdot \mathrm{kg}^{-1} \cdot \mathrm{min}^{-1}\right)$ and defenders $\left(56.1 \pm 5.1 \mathrm{ml}^{-1} \cdot \mathrm{kg}^{-1} \cdot \mathrm{min}^{-1}\right)$.

\begin{tabular}{|c|c|c|c|c|c|}
\hline \multicolumn{6}{|c|}{$\begin{array}{c}\text { Table } 1 \\
\text { Physical and anthropometric characteristics of soccer players }\end{array}$} \\
\hline \multirow{2}{*}{ Variable } & Goalkeepers & Defenders & Midfielders & Strikers & \multirow{2}{*}{$p$} \\
\hline & $\mathrm{n}=5$ & $\mathrm{n}=6$ & $\mathrm{n}=12$ & $\mathrm{n}=4$ & \\
\hline Stature $(\mathrm{cm})$ & $178.8 \pm 4.8$ & $172.4 \pm 4.8$ & $165.1 \pm 6.1$ & $167.1 \pm 6.5$ & $.001^{*}$ \\
\hline Body mass (kg) & $77.5 \pm 9.7$ & $68.2 \pm 6.5$ & $63.2 \pm 6.5$ & $60.2 \pm 9.5$ & $.007^{*}$ \\
\hline $\mathrm{BMI}\left(\mathrm{kg} \cdot \mathrm{m}^{-2}\right)$ & $24.2 \pm 2.2$ & $22.9 \pm 1.6$ & $23.2 \pm 2.2$ & $21.6 \pm 1.9$ & .307 \\
\hline Body fat $(\%)$ & $11.3 \pm 2.3$ & $10.0 \pm 1.7$ & $9.1 .0 \pm 0.9$ & $9.8 \pm 1.7$ & .312 \\
\hline Sit-and-reach $(\mathrm{cm})$ & $37.1 \pm 4.3$ & $45.1 \pm 4.9$ & $45.9 \pm 5.4$ & $40.1 \pm 3.4$ & .142 \\
\hline $\begin{array}{l}\text { Sit-ups (number per } \\
\text { minute) }\end{array}$ & $65.1 \pm 21.1$ & $54.8 \pm 4.9$ & $50.8 \pm 6.8$ & $45.3 \pm 2.9$ & .120 \\
\hline $\begin{array}{l}\text { Push-ups (number per } \\
\text { minute) }\end{array}$ & $31.5 \pm 4.9$ & $29.5 \pm 13.8$ & $45.4 \pm 17.3$ & $43.3 \pm 11.2$ & .203 \\
\hline Agility-T-test (s) & $10.4 \pm 0.0$ & $10.1 \pm 0.4$ & $10.3 \pm 0.6$ & $10.6 \pm 0.3$ & .484 \\
\hline $40 \mathrm{~m}$ sprint (s) & $5.5 \pm 0.0$ & $5.4 \pm 0.1$ & $5.5 \pm 0.4$ & $5.4 \pm 0.2$ & .687 \\
\hline $\mathrm{VO}_{2 \max }\left(\mathrm{ml}^{-1} \cdot \mathrm{kg}^{-1} \cdot \mathrm{min}^{-1}\right)$ & $47.9 \pm 0.2$ & $56.1 \pm 5.1$ & $57.2 \pm 3.1$ & $49.8 \pm 6.2$ & $.008^{*}$ \\
\hline \multicolumn{6}{|c|}{ * Significant at $p<0.05$} \\
\hline
\end{tabular}




\section{Discussion}

The results of this study showed that goalkeepers and defenders were the tallest and heaviest players. These findings are consistent with those of previous studies (Adeniran et al., 2009; Clark, 2007). Larger and heavier individuals are best suited as goalkeepers and defenders as it gives them an advantage in competing for aerial balls during matches, thereby leading to a compact goal defence. The midfielders were reported to be the shortest. Previous studies (Bangsbo, 1994; Reilly et al., 2000) had demonstrated that leaner players who were more mobile performed best as outfield players.

Our results further indicated that goalkeepers had the highest body fat percentage. Rico-Sanz (1998) proposed that a body fat percentage for soccer players should be around $10 \%$. However, the highest percentage of body fat found among goalkeepers in the present study could be related to the fact that they were not professional soccer players. They were university students who were probably not as involved as elite professional players in the rigorous training required to successfully play the game (Adeniran et al., 2009).

The midfielders had the least percentage of body fat when compared to those in other playing positions. This could be attributed to the fact that midfielders cover longer distances than defenders and strikers during matches. Midfielders mainly perform the critical function of linking attackers to defenders (and vice versa); therefore, a decrease in body mass could be beneficial for that purpose (Silvestre et al., 2006). As Kashani et al. (2013) stated, in the phase of the attack, the midfielders take a ball to the opponent's half, whereas the defenders, in most cases, make a slight shift forward, and the attackers wait for the ball from the midfielders. In the defensive phase, the attackers run (short runs at low intensity), the midfielders run back, and the defenders wait for the opposing players. Therefore, it is important for midfielders to have physical characteristics that are complementary to their performance of specific roles in the team.

The greater values of $\mathrm{VO}_{2 \max }$ found in midfielders compared with goalkeepers, defenders, and strikers are consistent with those of previous studies (Gil et al., 2010; Reilly et al., 2000). Reilly (1996) reported that the mean values of $\mathrm{VO}_{2 \max }$ for soccer players should range between 56 and $69 \mathrm{ml}^{-1} \cdot \mathrm{kg}^{-1} \cdot \mathrm{min}^{-1}$. The mean values for players in the present study ranged between 47.9 and $57.2 \mathrm{ml}^{-1} \cdot \mathrm{kg}^{-1} \cdot \mathrm{min}^{-1}$, which are noticeably lower than those reported by Reilly (1996). Such discrepancy could be explained on the basis that the current study exclusively consisted of amateur soccer players. Previous research (Rebelo et al., 2010) found a distinction between the mean values of $\mathrm{VO}_{2 \max }$ for professional and amateur players, with professional soccer players performing better than their amateur counterparts. The authors further argued that due to the players' high level of competition, they were more likely to be exposed to effective and advanced quality training, thus leading to a better development of their aerobic capacities. Another possible explanation for the relatively low $\mathrm{VO}_{2 \text { max }}$ among soccer players could be that they were tested during the pre-season. The results may have been different were they tested during the in-season.

Soccer players continuously change the direction of movement and body position during a match (Clark, 2007). The strikers and goalkeepers performed better in agility than midfielders and defenders. The reason strikers were agile could be due to the fact that they always run and turn at high intensity. Conversely, it is not surprising that goalkeepers perform well in agility as they need to move their bodies quickly and change the direction in order to guard the goal (Clark, 2007). Overall, there were no significant differences in all the variables (except body height, body mass, and $\mathrm{VO}_{2 \max }$ ) among players according to the playing positions. It is mandatory to make positional evaluations in terms of physical and anthropometric characteristics in soccer before players are assigned different roles. The fact that there were no significant differences among the players according to their playing positions could be due to different methods used and lack of positional specificity in terms of physical conditioning.

The results of this study have important limitations. First, there were few participants in each of the playing positions, which confound the generalisation of our results. Second, the study was conducted in only one university, with the male players involved in an amateur league. Hence, this limits the generalisation of the results 
to other universities in South Africa. It is therefore suggested that future studies should increase players' sample size in the various playing positions in order to more clearly elucidate the results. In addition, such studies should focus comprehensively on investigating the physical and anthropometric characteristics not studied in the present study, such as a vertical jump and anthropometric somatotypes.

\section{Conclusion}

This study found that goalkeepers and defenders were the tallest and heaviest players. The midfielders were reported to be shortest of all the cohorts of players. Our results further indicated that goalkeepers had the highest body fat percentage, while the midfielders were slimmest. Of great concern is that no significant differences were observed among players in all other variables according to the playing positions, with the exception of body height, body mass, and $\mathrm{VO}_{2 \max }$. Nevertheless, the results of this study could help coaches and sports scientists to tailor their training programmes based on the physical and anthropometric requirements of specific playing positions for successful soccer performance.

\section{References}

Adeniran SA, Amusa LO, Toriola AL, Adeyanju SA. Anatomical fat patterning in male Nigerian soccer players. Afri J Phys Health Educ Recreat Dance, 2009; 15(2): 285-293

Bangsbo J. The physiology of soccer: With special reference to intense intermittent exercise. Acta Physiol Scand Suppl, 1994; 619: 1-156

Bangsbo J, Nørregaard L, Thorsø F. Activity profile of competition soccer. Can J Sport Sci, 1991; 16(2) 110-116

Casajús JA. Seasonal variation in fitness variables in professional soccer players. J Sports Med Phys Fitness, 2001; 41(4): 463-469

Clark JR. Positional assessment and physical fitness characteristics of male professional soccer players in South Africa. Afri J Phys Health Educ Recreat Dance, 2007; 13(4): 453-464

Ellis L, Gastin P, Lawrence S, Savage B, Sheales A, Stapff A, Tumility D, Quinn SW, Young W. Protocols for the physiological assessment of team sport players. In CJ Gore (Ed.), Physiological tests for elite athletes. Champaign, IL: Human Kinetics, 128-144; 2000

Gil SM, Gil J, Ruiz F, Irazusta A, Irazusta J. Anthropometrical characteristics and somatotype of young soccer players and their comparison with the general population. Biol Sport, 2010; 27: 17-24

Helgerud J, Engen LC, Wisløff U, Hoff J. Aerobic endurance training improves soccer performance. Med Sci Sport Exerc, 2001; 33(11): 1925-1931

Jackson AW, Fromme C, Plitt H, Mercer J. Reliability and validity of a 1-minute push-up test for young adults. Res Q Exerc Sport, 1994; 65 (Suppl.): A57-A58

Johnson BL, Nelson JK. Practical Measurements for Evaluation in Physical Education. Minneopilis: Burgess Publishing; 2000

Kashani A, Khotbesara RD, Maskooni MD, Djafarian K. Body composition of elite Iranian soccer players according to the playing position. Int Res J Appl Basic Sci, 2013; 7 (14): 1184-1188

Kubayi NA, Coopoo Y, Morris-Eyton HF. Job-related barriers encountered by football coaches in Gauteng Province of South Africa. Afri J Phys Health Educ Recreat Dance, 2015; Nov (Suppl.): 2015; 160-166

Marfell-Jones M, Olds T, Stew A, Carter L. International Standards for Anthropometric Assessment. Australia: The International Society for the Advancement of Kinanthropometry; 2006

Ramsbottom R, Brewer J, Williams C. A progressive shuttle run test to estimate maximal oxygen uptake. $\mathrm{Br} J$ Sports Med, 1988; 22: 141-144

Rebelo M, Smylie C, Macintosh S, Lombard R. Selected physical attributes of male soccer players: A comparative analysis. Afri J Phys Health Educ Recreat Dance, 2010; 16(4): 85-92 
Reilly T. Science and Soccer. London: E \& FN Spon; 1996

Reilly T, Bangsbo T, Franks A. Anthropometric and physiological predispositions for elite soccer. J Sport Sci, 2000; 18: 669-683

Rico-Sanz J. Body composition and nutritional assessment in soccer. Int J Sport Nutr, 1998; 8(2): 113-123

Ross WD, Marfell-Jones MJ. Kinanthropometry. In JD MacDougall, HA Wenger, HJ Green (Eds.), Physiological testing of the high-performance athlete. Champaign, IL, USA: Human Kinetics, 223-308; 1991

Silvestre R, West C, Maresh CM, Kraemer WJ. Body composition and physical performance in men's soccer: A study of a national collegiate athletic association division I team. J Strength Cond Res, 2006; 20(1): 177-183

Williams AM, Franks A. Talent identification in soccer. Sports Exerc Inj, 1998; 4: 159-165

\title{
Corresponding author:
}

\author{
Alliance Kubayi \\ Tshwane University of Technology \\ Department of Sport, Rehabilitation and Dental Sciences \\ Republic of South Africa \\ Pretoria, 0001 \\ Phone number: +27 123824272 \\ Fax number: +27 123825801 \\ E-mail address: kubayina@tut.ac.za
}

